\title{
Minimization of Torque Ripple in DTC of Induction Motor Using Fuzzy Mode Duty Cycle Controller
}

\author{
Turki Y. Abdalla \\ Dept. of Computer Engineering \\ College of Engineering \\ University of Basrah \\ Basrah-IRAQ
}

\author{
Haroution Antranik Hairik \\ Dept. of Computer Engineering \\ College of Engineering \\ University of Basrah \\ Basrah -IRAQ
}

\author{
Adel M. Dakhil \\ Dept. of Electrical Engineering \\ College of Engineering \\ University of Basrah \\ Basrah -IRAQ
}

\begin{abstract}
Among all control methods for induction motor drives, Direct Torque Control (DTC) seems to be particularly interesting being independent of machine rotor parameters and requiring no speed or position sensors. The DTC scheme is characterized by the absence of PI regulators, coordinate transformations, current regulators and PWM signals generators. In spite of its simplicity, DTC allows a good torque control in steady state and transient operating conditions to be obtained. However, the presence of hysterics controllers for flux and torque could determine torque and current ripple and variable switching frequency operation for the voltage source inverter. This paper is aimed to analyze DTC principles, and the problems related to its implementation, especially the torque ripple and the possible improvements to reduce this torque ripple by using a proposed fuzzy based duty cycle controller. The effectiveness of the duty ratio method was verified by simulation using Matlab/Simulink software package. The results are compared with that of the traditional DTC models.
\end{abstract}

\section{INTRODUCTION}

More than a decade ago, direct torque control (DTC) was introduced to give a fast and a good dynamic torque response and can be considered as an alternative to the field oriented control (FOC) technique [1-3].

These control strategies are different in the operation principle but their objectives are the same. They aim both to control effectively the motor torque and flux in order to force the motor to accurately track the command trajectory regardless of the machine and load parameter variation or any external disturbances[4].

In DTC of induction motors it is possible to control the stator flux, and the developed electromagnetic torque by selecting optimum inverter switching modes[5].

Common disadvantages of the conventional DTC are high torque ripple and slow transient response to the step changes in torque during start-up. Several technique have been developed to improved the torque performance [5-10]. In classical DTC induction motor drive there are torque and flux ripples because none of the inverter switching vectors is able to produce the desired changes in both torque and stator flux. However other various techniques are used which can reduce the torque ripples in the developed electromagnetic torque and stator flux. Some of these techniques involve the usage of high switching frequencies or the change of the inverter topology, but it is also possible to use schemes which do not involve any of the mentioned technique, such as the duty ratio control [11].

In this paper a fuzzy controller is used to obtain a duty-ratio that can be used to minimize the torque ripple, simulation results show that the torque ripple is significantly reduced when compared with the classical DTC.

\section{INDUCTION MOTOR MODEL}

In stationary reference frame, space voltage vector of both stator and rotor of the machine are represented as follows

$$
\begin{aligned}
& \bar{V}_{s}=r_{s} \cdot \bar{i}_{s}+\frac{d \bar{\varphi}_{s}}{d t} \\
& 0=r_{r} \cdot \bar{i}_{r}+\frac{d \bar{\varphi}_{r}}{d t}-j w \bar{\varphi}_{s} \\
& \varphi_{s}=L_{s} i_{s}+M i_{r} \\
& \varphi_{r}=M \cdot i_{s}+L_{r} i_{r}
\end{aligned}
$$

where $r_{s}$, and $r_{r}$ are stator and rotor resistances, $V_{s}$ is the stator space voltage vectors, $\bar{\varphi}_{s}$ and $\bar{\varphi}_{r}$ are stator and rotor flux respectively. $\mathrm{w}$ is the angular speed of the rotor. 


\section{VECTOR MODEL OF THE INVERTER OUTPUT VOLTAGE}

In a voltage fed three phase, the switching commands of each inverter leg are complementary. So for each leg a logic state $C_{i}(i=1,2,3)$ can be defined. $\mathrm{C}_{\mathrm{i}}$ is 1 if the upper switch is commanded to be closed and 0 if the lower one in commanded to be closed (first). Since there are 3 independent legs there will be eight different states, so 8-different voltages. Applying the vector transformation described as [12].

$V_{s}=\sqrt{\frac{2}{3}} \cdot V_{d} \cdot\left[C_{1}+C_{2} \cdot e^{\frac{j 2 \pi}{3}}+C_{3} \cdot e^{\frac{j 4 \pi}{3}}\right]$

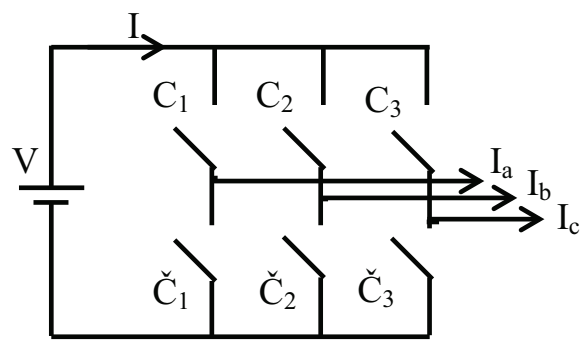

Fig.(1) Three phase voltage inverter

\section{DIRECT TORQUE CONTROL PRINCIPLES}

It is well known that in the three phase induction motors the electromagnetic torque can be expressed as follows [11]

$$
T e=\frac{3}{2} \cdot P \frac{L_{m}}{L_{s} \cdot L_{r}-L_{m}{ }^{2}} \cdot\left|\bar{\varphi}_{s}\right| \cdot\left|\bar{\varphi}_{r}\right| \cdot \sin \left(\theta_{s}-\theta_{r}\right)
$$

where $\theta_{s}$, and $\theta_{r}$ are the respective angles of stator and rotor fluxes respectively , $\mathrm{P}$ is the number of pair poles, and $\mathrm{L}_{\mathrm{s}}, \mathrm{L}_{\mathrm{r}}, \mathrm{L}_{\mathrm{m}}$ are the stator, rotor, and mutual reactance respectively. In equation (1) for simplicity, it is assumed that the stator voltage drop $\mathrm{r}_{\mathrm{s}} \mathrm{i}_{\mathrm{s}}$ is small and negligible, then the stator flux variation can be expressed as

$$
\Delta \bar{\varphi}_{S}=\bar{V}_{s} \cdot \Delta t
$$

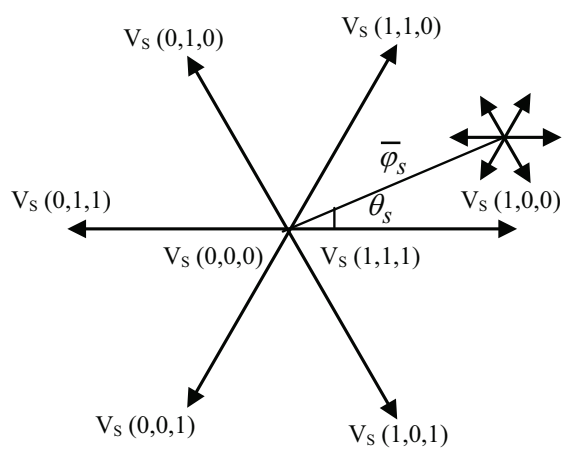

Fig. (2) Voltage Space Vector Representation

As shown in Fig.(2) the selection of the voltage vector depends on the position of stator flux linkage. The choice goal is to limit the flux and torque within the hysterics bands around their references values[13].With this type of corrector, in spite of its simplicity, one can easily control and maintain the end of the vector flux, in a circular ring[12].

The stator flux linkage command signal either increases or decreases in the controller circuit while the torque command signal either increases/decreases or it may stay constant. A table with 36 states can be constructed as it is shown in Table (1)[14].

Table (1) The switching table for the DTC

\begin{tabular}{|l|l|l|l|l|l|l|l|}
\cline { 2 - 8 } \multicolumn{1}{c|}{} & sectors & 1 & 2 & 3 & 4 & 5 & 6 \\
\hline \multirow{4}{*}{ flux } & Torque & & & & & & \\
\hline \multirow{4}{*}{$\Delta \varphi=1$} & $\Delta T=1$ & $\mathrm{~V}_{2}$ & $\mathrm{~V}_{3}$ & $\mathrm{~V}_{4}$ & $\mathrm{~V}_{5}$ & $\mathrm{~V}_{6}$ & $\mathrm{~V}_{1}$ \\
\cline { 2 - 9 } & $\Delta T=0$ & $\mathrm{~V}_{7}$ & $\mathrm{~V}_{0}$ & $\mathrm{~V}_{7}$ & $\mathrm{~V}_{0}$ & $\mathrm{~V}_{7}$ & $\mathrm{~V}_{0}$ \\
\cline { 2 - 8 } & $\Delta T=-1$ & $\mathrm{~V}_{6}$ & $\mathrm{~V}_{1}$ & $\mathrm{~V}_{2}$ & $\mathrm{~V}_{3}$ & $\mathrm{~V}_{4}$ & $\mathrm{~V}_{5}$ \\
\hline \multirow{4}{*}{$\Delta \varphi=0$} & $\Delta T=1$ & $\mathrm{~V}_{3}$ & $\mathrm{~V}_{4}$ & $\mathrm{~V}_{5}$ & $\mathrm{~V}_{6}$ & $\mathrm{~V}_{1}$ & $\mathrm{~V}_{2}$ \\
\cline { 2 - 9 } & $\Delta T=0$ & $\mathrm{~V}_{0}$ & $\mathrm{~V}_{7}$ & $\mathrm{~V}_{0}$ & $\mathrm{~V}_{7}$ & $\mathrm{~V}_{0}$ & $\mathrm{~V}_{7}$ \\
\cline { 2 - 9 } & $\Delta T=-1$ & $\mathrm{~V}_{5}$ & $\mathrm{~V}_{6}$ & $\mathrm{~V}_{1}$ & $\mathrm{~V}_{2}$ & $\mathrm{~V}_{3}$ & $\mathrm{~V}_{4}$ \\
\hline
\end{tabular}

\section{STATOR FLUX AND TORQUE ESTIMATION}

From the first principles of the DTC [15]

$$
\begin{aligned}
& \varphi_{s \alpha}=\int\left(\bar{V}_{s}-\bar{I}_{s \alpha} \cdot r_{s}\right) \cdot d t \\
& \varphi_{s \beta}=\int\left(\bar{V}_{s}-\bar{I}_{s \beta} \cdot r_{s}\right) \cdot d t
\end{aligned}
$$


The components of the current $\left(I_{s \alpha}, I_{s \beta}\right)$ and stator voltages ( $V_{s \alpha}, V_{s \beta}$ ) are obtained by [1]

$$
\begin{gathered}
I_{s \alpha}=\sqrt{\frac{2}{3}} \cdot I_{s a} \\
I_{s \beta}=\frac{1}{\sqrt{2}} \cdot\left(I_{s b}-I_{s c}\right) \\
V_{s \alpha}=\sqrt{\frac{2}{3}} \cdot V_{d} \cdot\left(C_{1}-\frac{1}{2}\left(C_{2}+C_{3}\right)\right) \\
V_{s \beta}=\frac{1}{\sqrt{2}} \cdot V_{d} \cdot\left(C_{2}-C_{3}\right)
\end{gathered}
$$

Since $\alpha$ 's , $\beta$ 's components are perpendiculars the stator flux linkage is given by

$$
\varphi_{s}=\sqrt{\varphi^{2}{ }_{s \alpha}+\varphi_{s \beta}^{2}}
$$

and the flux angle is given by

$$
\angle \bar{\varphi}_{s}=\tan ^{-1}\left(\frac{\varphi_{s \beta}}{\varphi_{s \alpha}}\right)
$$

The electromagnetic torque is given by

$$
T_{e}=\frac{3}{2} \cdot P \cdot\left(\varphi_{s \alpha} \cdot i_{s \beta}-\varphi_{s \beta} \cdot i_{s \alpha}\right)
$$

\section{DUTY RATIO CONTROL}

The direct torque control has many promising features and advantages like absence of speed and position sensors, absence of coordinate transformation, reduced number of controller, minimal torque response time[5]. In spite of this advantages a major draw back of classical DTC is high torque and flux ripple because of none of the inverter switching vector is able to produce the exact stator voltage. However, if instead of applying a voltage vector for the entire switching period, it is applied for apportion of the switching period and the zero switching state is applied for the rest of the period in which the ripples can be reduced. This is defined as duty ratio control in which the portion of switching period for which a non zero voltage vector is applied is known as the duty ratio $\delta$. and ratio $(\delta)$ is varied between 0 and 1 .

\section{FUZZY LOGIC DTC CONTROLLER}

Since the duty ratio during each switching state is a nonlinear function of a number of factors : torque error $\left(\mathrm{E}_{\mathrm{te}}=\mathrm{T}_{\text {ref }}-\mathrm{T}_{\mathrm{e}}\right)$, flux error $\left(\mathrm{E}_{\psi}=\bar{\varphi}_{r e f}-\varphi_{S} \quad\right)$ and flux position $(\theta)$, it is difficult to represent mathematically the relation between the three variables. The fuzzy logic control seems to be a reasonable choice to determine the duty ratio during each switching state[5]. The diagram of direct torque control with a fuzzy duty ratio control is shown in figure(3) below

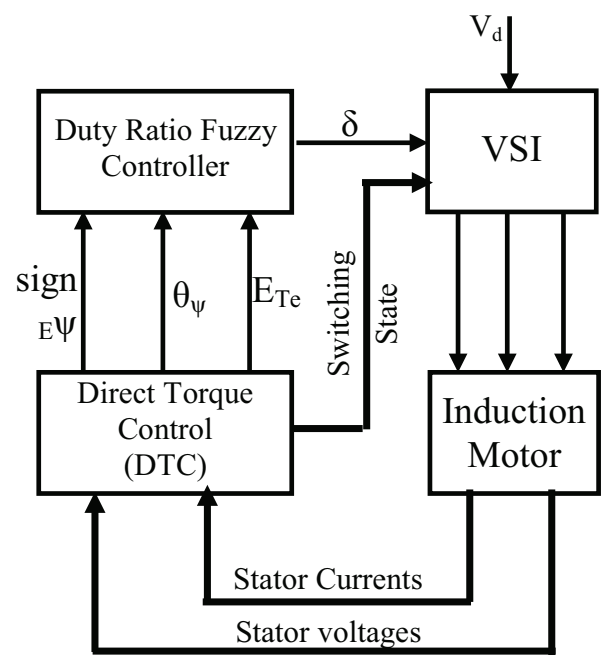

Fig.(3)Block diagram of fuzzy duty ratio control

In general, a fuzzy logic controller consist of three main parts : fuzzification, fuzzy reasoning (based on fuzzy rules), and defuzzification. This system is known as Mamdani system shown in figure(4)

\section{A Fuzzification}

The torque error, and stator flux angle are given as input variables to fuzzy controller and output variable is duty ratio control $(\delta)$. The symbols used in memberships refers to the following linguistic term

Table(2) Linguistic term for torque error

\begin{tabular}{|c|c|}
\hline Linguistic Term & Symbol \\
\hline Small & S \\
\hline Medium & M \\
\hline Large & L \\
\hline
\end{tabular}


Table(3) Linguistic term for flux position

\begin{tabular}{|c|c|}
\hline Linguistic Term & Symbol \\
\hline Small & S \\
\hline Medium & $\mathrm{M}$ \\
\hline Large & $\mathrm{L}$ \\
\hline
\end{tabular}

Table(4) Linguistic term for duty ratio control

\begin{tabular}{|c|c|}
\hline Linguistic Term & Symbol \\
\hline Small & $\mathrm{S}$ \\
\hline Medium & $\mathrm{M}$ \\
\hline Large & $\mathrm{L}$ \\
\hline
\end{tabular}

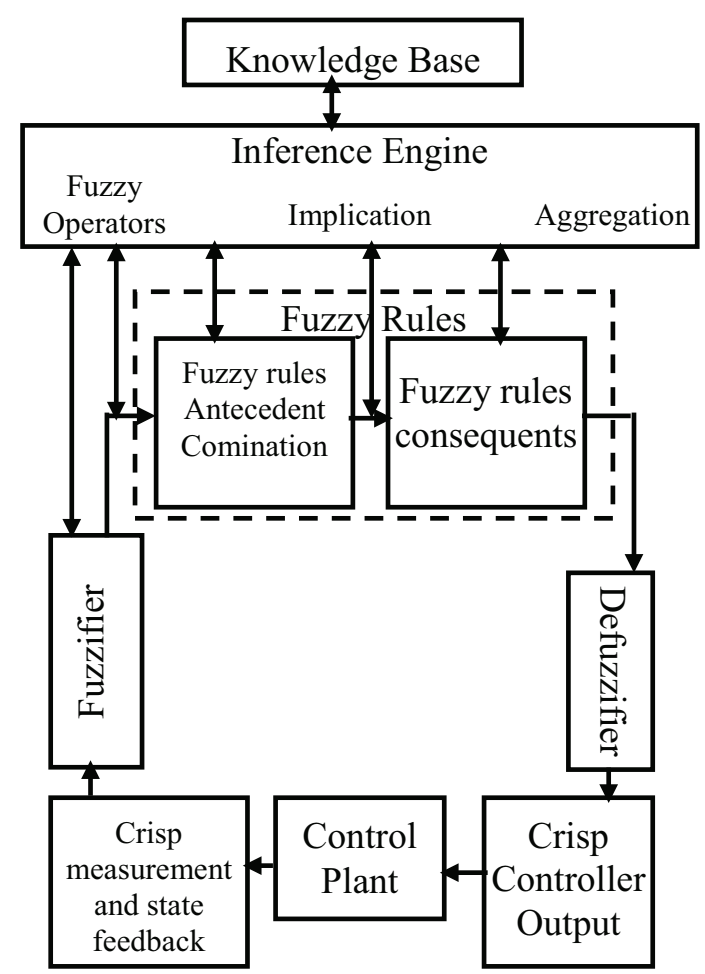

Fig. (4) Mamdani fuzzy logic controller
The input and output variable membership functions are shown in figure(5) below

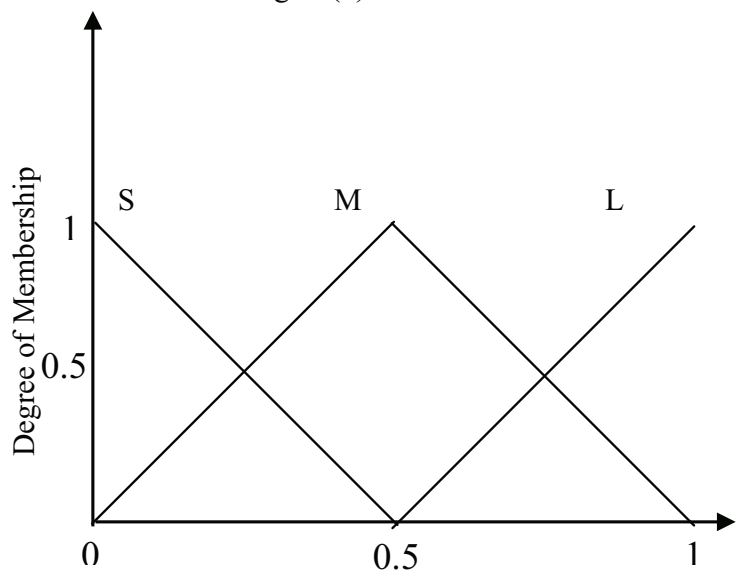

(a) Torque error

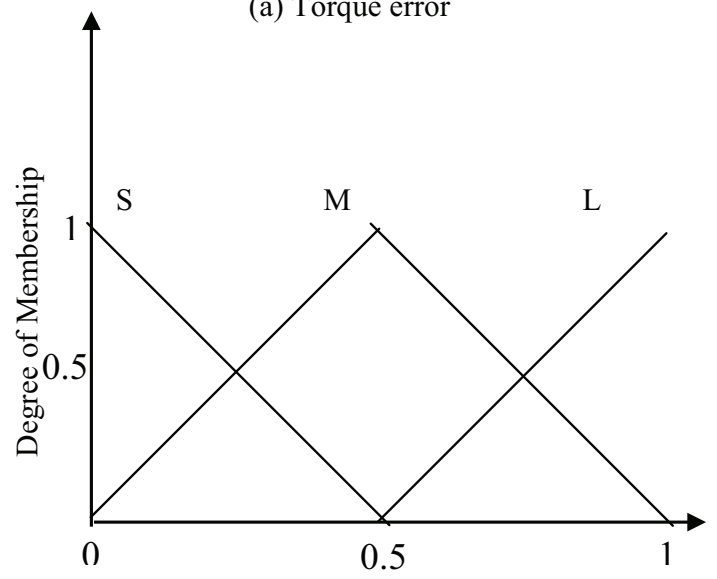

(b) Flux Position

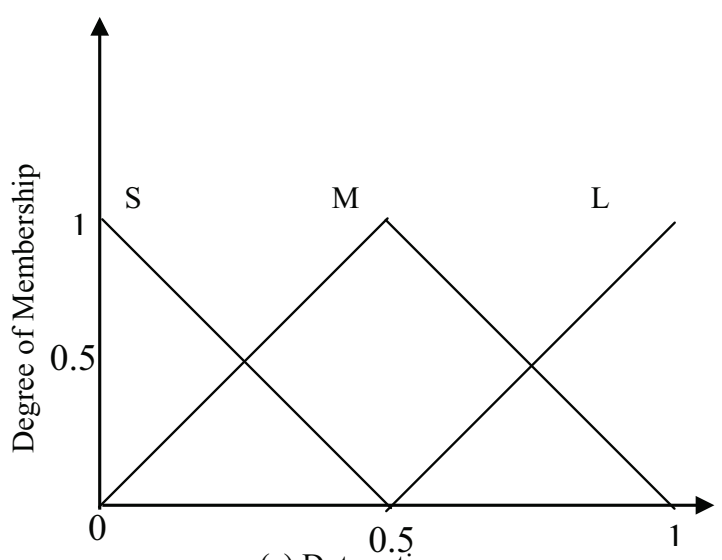

(c) Duty ratio

Fig.(5) Input and output membership functions 


\section{$B$ Fuzzy reasoning and control rules}

Fuzzy logic is well suitable to implement control rules that can only be expressed verbally for a system that can not be modeled with linear differential equations. Fuzzy rules are conditional statement that use fuzzy operators and membership functions to make control decisions[16]. Control rules are often expressed in the If-Then format. The $i^{\text {th }}$ rules $R_{i}$ can be written as

$R_{i}$ : If $E_{\text {te }}$ is $A i$ and $\theta$ is $B_{i}$ then $\delta$ is $C_{i}$

Where $A_{i}, B_{i}$, and $C_{i}$ denote the fuzzy set. $i=1$ to 9 , there are 9 reason rule .Combines the terms in the antecedent part of the fuzzy rules by using minimum operators, and the term in the consequent part with maximum operators.

Table(5) Fuzzy control linguistic roles for duty ratio

\begin{tabular}{|c|c|c|c|c|}
\hline \multicolumn{5}{|c|}{ control } \\
\hline $\mathrm{E}_{\psi}$ & $\theta E_{T e}$ & S & $\mathrm{M}$ & $\mathrm{L}$ \\
\hline \multirow{3}{*}{$\begin{array}{c}\text { Flux }> \\
\text { Ref. } \\
\text { Flux }\end{array}$} & $\mathrm{S}$ & $\mathrm{S}$ & $\mathrm{S}$ & $\mathrm{M}$ \\
\hline & $\mathrm{M}$ & $\mathrm{S}$ & $\mathrm{M}$ & $\mathrm{L}$ \\
\hline & $\mathrm{L}$ & $S$ & $\mathrm{M}$ & $\mathrm{L}$ \\
\hline \multirow{3}{*}{$\begin{array}{c}\text { Flux }< \\
\text { Ref. } \\
\text { Flux }\end{array}$} & S & $\mathrm{S}$ & $\mathrm{M}$ & $\mathrm{L}$ \\
\hline & $\mathrm{M}$ & $\mathrm{S}$ & $\mathrm{M}$ & $\mathrm{L}$ \\
\hline & L & $\mathrm{M}$ & $\mathrm{L}$ & $\mathrm{L}$ \\
\hline
\end{tabular}

\section{Defuzzification}

To obtain the output of the fuzzy controller, the method of center of area (COA) is used. Using this method, the crisp output, $\delta$ is chosen as the center of area for the membership function of the overall implied fuzzy set B. for continuous output of the universe of discourse the center of area output is denoted by

$$
\delta=\frac{\int_{\delta} \delta \cdot \mu_{B}^{\sim}(\delta) d \delta}{\int_{\delta} \mu_{B}^{\sim}(\delta) d \delta}
$$

VIII. SIMULATION RESULTS

A simulink model for a DTC of induction motor drive system with fuzzy duty ratio based controller is implemented using the well known Matlab/Simulink software package, as shown in Fig. (6).

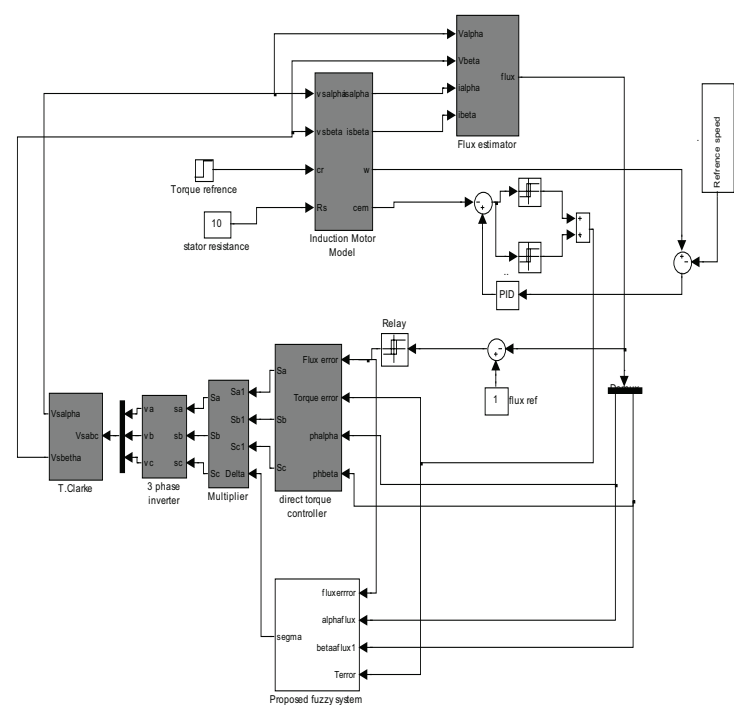

Fig.(6) Simulink model of the proposed system

The parameters of the induction motor used in this work are given in Table (6)

Table(6) Parameters of the Induction motor

\begin{tabular}{|c|c|}
\hline Rated Voltage & $380 \mathrm{~V}$ \\
\hline Maximum Torque & $15 \mathrm{~N} . \mathrm{m}$. \\
\hline Poles & 4 \\
\hline Rated Speed & $1440 \mathrm{RPM}$ \\
\hline Stator Resistance & $1.2 \Omega$ \\
\hline Rotor Resistance & $1.8 \Omega$ \\
\hline Stator Leakage Inductance & $0.1554 \mathrm{H}$ \\
\hline Rotor Leakage Inductance & $0.1568 \mathrm{H}$ \\
\hline Mutual Inductance & $0.15 \mathrm{H}$ \\
\hline Moment of Inertia & 1.662 \\
\hline
\end{tabular}

Figures (8) and (10) show the torque step response of the motor at $200 \mathrm{rad} / \mathrm{sec}$ for the classical DTC and the proposed one respectively. For the classical one, the torque ripple after loading rises to an average of \pm 18 N.m. while that for the proposed is \pm 10 N.m.

Figures (7) and (10) show the corresponding speed response for both cases. The stator current in classical and the proposed control scheme are shown in Figs. (9) and (12) respectively. The improvement in the speed response is well declared. For different loading conditions the torque, phase current and speed responses are shown through Figs.(13-18) for both the conventional DTC and the fuzzy based duty cycle controllers, which appreciates that the torque ripple decreases when the proposed scheme is used. 


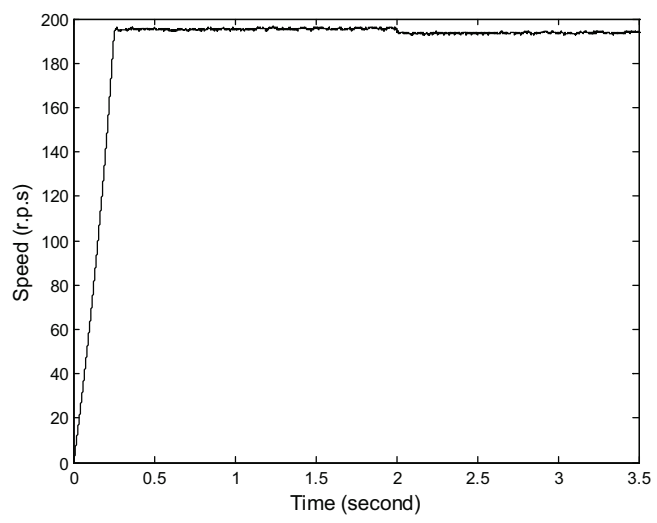

Fig. (7) Speed response for classical DTC with a step change of 5 N.m. at $2 \mathrm{sec}$.

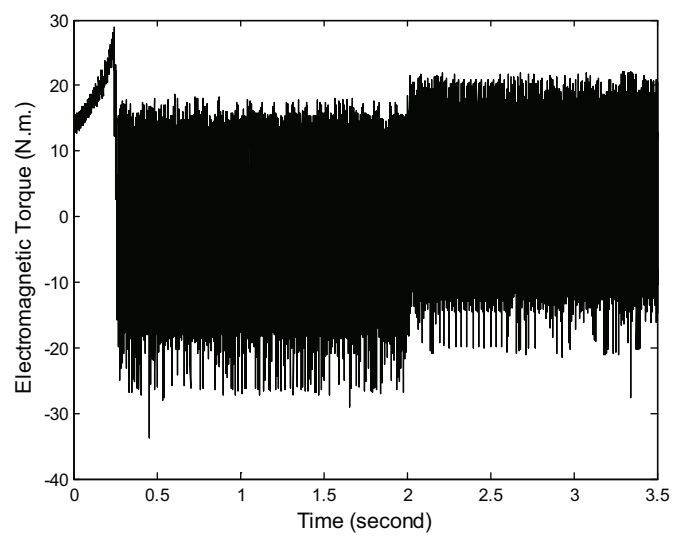

Fig.(8) Electromagnetic torque response with a step change of $5 \mathrm{~N} . \mathrm{m}$. at $2 \mathrm{sec}$ for classical DTC.

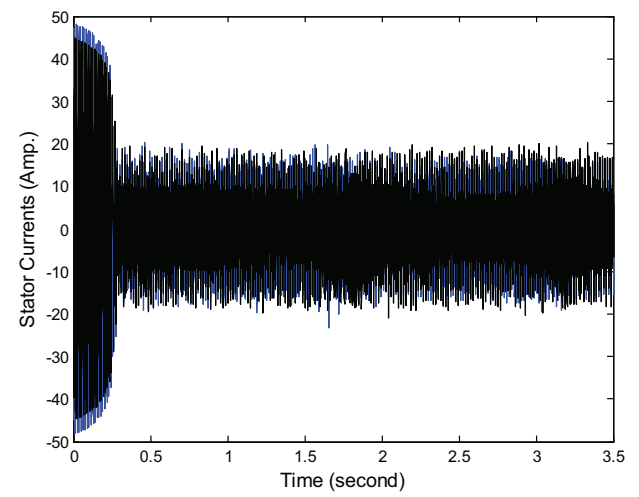

Fig.(9) Stator current for three phase induction machine for classical DTC

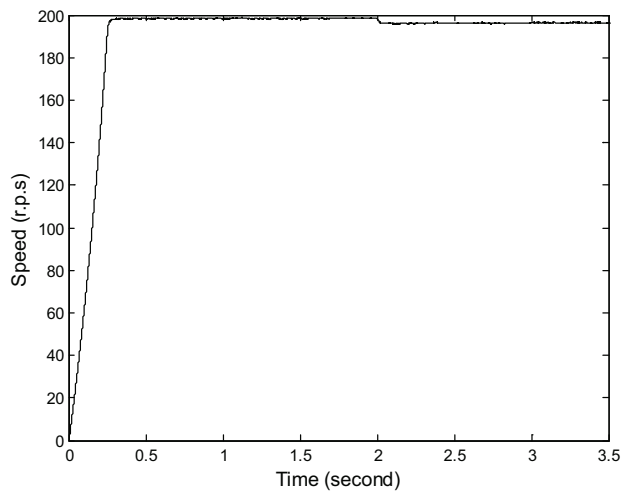

Fig.(10) Speed response for the proposed controller with a step change of $5 \mathrm{~N} . \mathrm{m}$. at $2 \mathrm{sec}$

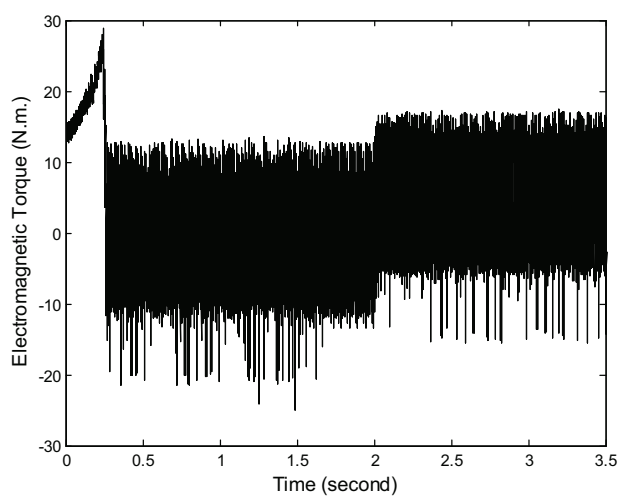

Fig.(11) Electromagnetic torque response for the proposed controller with a step change of $5 \mathrm{~N} . \mathrm{m}$. at $2 \mathrm{sec}$.

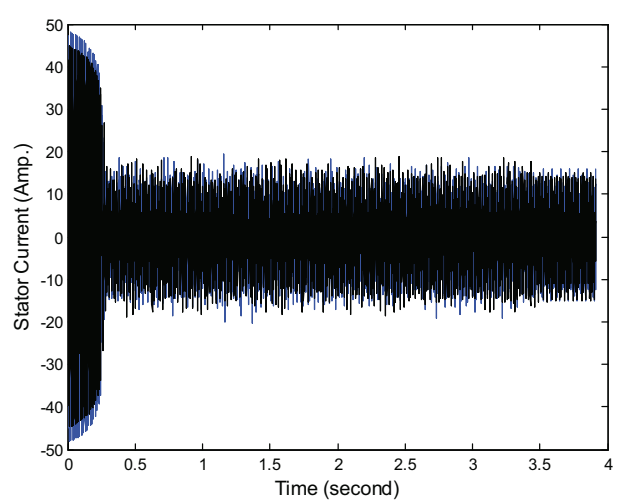

Fig.(12) Stator current for three phase induction machine for the proposed controller 


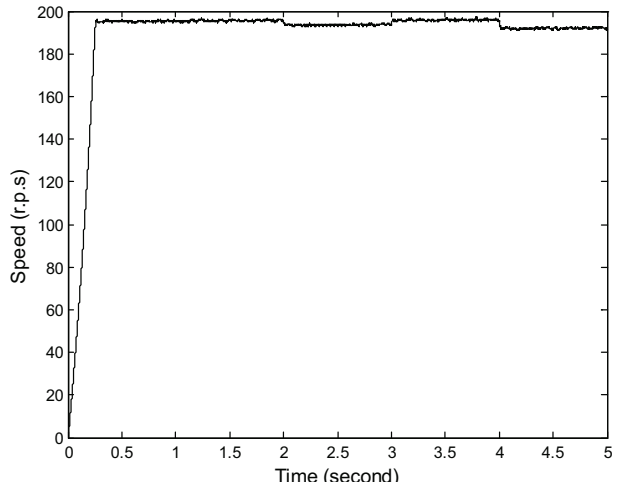

Fig.(13) Speed response for classical DTC with torque step change of $5 \mathrm{~N} . \mathrm{m}$. at $2 \mathrm{sec}$, 0 N.m. at $3 \mathrm{sec}$. and 10 N.m. at 4 second

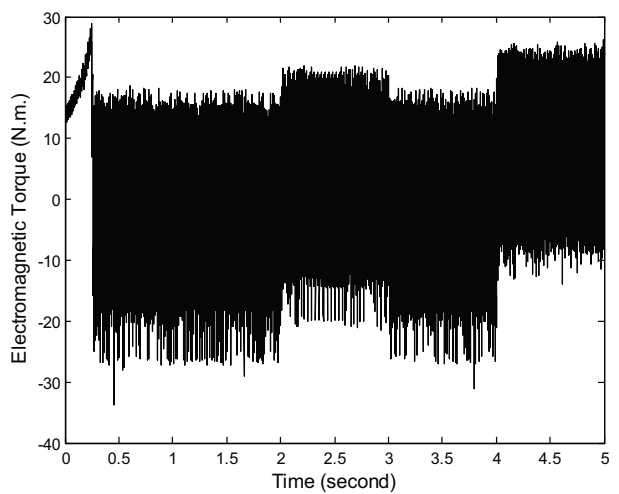

Fig.(14) Electromagnetic torque response for classical DTC with torque step change of $5 \mathrm{~N} . \mathrm{m}$. at $2 \mathrm{sec}$, 0 N.m. at 3 sec. and 10 N.m. at 4 second

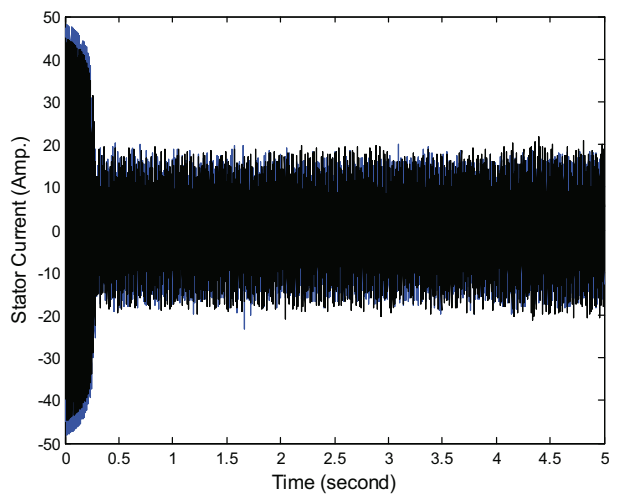

Fig.(15) Stator current for three phase induction machine with classical DTC with torque step change of 5 N.m. at $2 \mathrm{sec}$, 0 N.m. at $3 \mathrm{sec}$. and 10 N.m. at 4 second

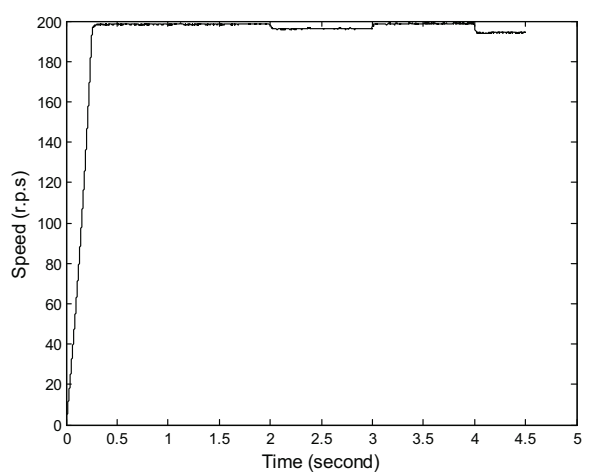

Fig.(16) Speed response for the proposed controller with torque step change of $5 \mathrm{~N} . \mathrm{m}$. at $2 \mathrm{sec}$, , 0 N.m. at 3 sec. and 10 N.m. at 4 second

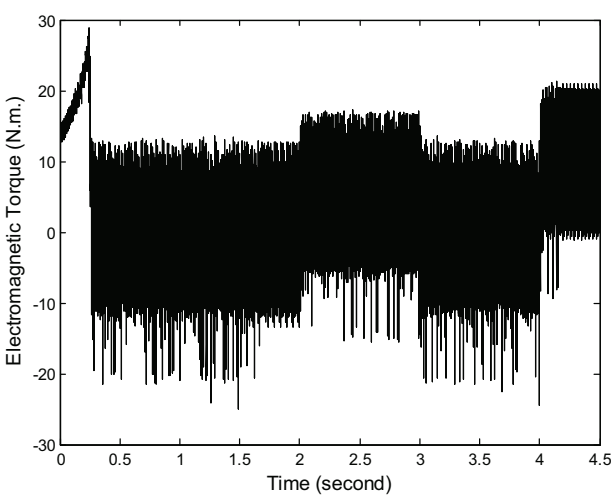

Fig. (17) Electromagnetic torque response for the proposed controller with torque step change of $5 \mathrm{N.m}$. at $2 \mathrm{sec}$, 0 N.m. at $3 \mathrm{sec}$. and 10 N.m. at 4 second

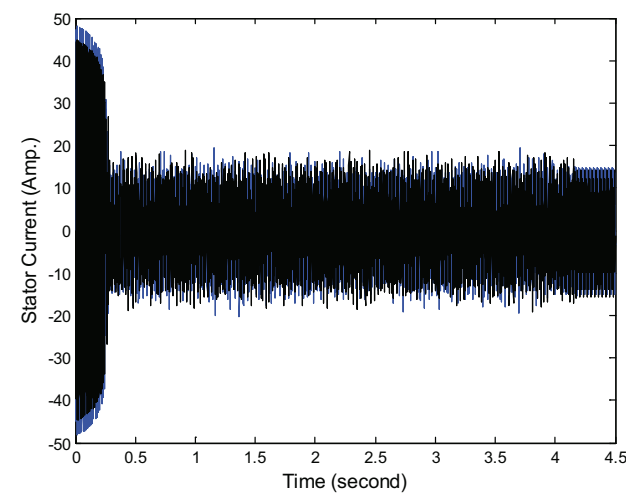

Fig.(18)Stator current for three phase induction machine for the proposed controller with torque step change of $5 \mathrm{~N} . \mathrm{m}$. at $2 \mathrm{sec}$, , 0 N.m. at $3 \mathrm{sec}$. and 10 N.m. at 4 second. 


\section{CONCLUSION}

In this paper a fuzzy based duty cycle controller of induction motor have been proposed. An improved torque response was achieved with the fuzzy based duty cycle controller than the conventional DTC. The performance has been tested by simulations. The main improvements shown are reduction of torque and current ripples in transient and steady state response.

\section{REFERENCES}

[1] Isao Takahashi, Toshihiko Nogughi , “ A New quick -response and high efficiency control strategy of an induction motor" , IEEE Trans. on Industry Applications , vol. 1A-22, no. 5 , September / October 1988 ,pp.820-827.

[2] P. Tiitinen , "The next generation motor control, DTC direct torque control ", Proc.of international conference on power electronics, drive and energy system for industrial growth new Delhi, India 1996, PP. 37-43 .

[3] Nik rumzi , Abdul halim mohd, Naziha Ahmed, “ Direct torque control of induction machine with constant switching frequency and improved stator flux estimation", IEEE pp.1-7.

[4] Hoang LE-Huy , " Comparison of field-oriented control and direct torque control for induction motor drives “, IEEE , 1999, pp. 1245-1252.

[5] Malik Elbuluk , " Torque ripple minimization in direct torque control of induction machines ", IEEE ,2003, pp.11-16.

[6] Habelter T. , Profumo F. , Pastorelli M. , Tolbert L. , "Direct torque control of induction machines using space vector modulation “, IEEE Transaction on industrial application Vol.28, no.5, 1992 , pp. 1045- 1053.

[7] Kang J. Sul S. , " New direct torque control of induction motor for minimum torque ripples and constant switching frequency ", IEEE Transaction on industrial application Vol.35, no.5, 1999, pp. 1076- 1082.

[8] Lin chen , Kang-Ling fang, Zi-Fan hu, "A scheme of fuzzy direct torque control for induction machine" , IEEE Proceeding of the fourth international conference on machine learning and cybernetics, Guangzhou, 18-21 August 2005, pp. 803- 807.

[9] Jia-Qiang Yang, Jin Huang, “ Direct torque control system for induction motors with fuzzy speed PI regulator", IEEE, Proceeding of the fourth international conference on machines learning and cybernetics ,Guangzhou , 1821 August 2005, pp.778-783.
[10] I.G. Bird , Zelaya De La Parra, “ Fuzzy logic torque ripple reduction for DTC based AC drives", IEEE Electronics letters ,Vol.33 , no. 17, $4^{\text {th }}$ August 1997, pp. 1501-1502

[11] Antoni Arias Pujol ," Improvements in direct torque control of induction motor" master thesis , university of polytechnic in catalunya, 2000.

[12] R. Toufouti , S. Meziane , H. Benalla , “ Direct torque control for induction motor using fuzzy logic" , ACSE Journal, Volume (6), issue (2), June, 2006.

[13] F. Sheidaei , M. Sedighizadeh S. H. MohseniZonoozi , Y. Alinejad-Beromi ," A fuzzy logic direct torque control for induction motor sensorless drive", Upec2007, pp.197-202.

[14] Marian P. Kazmierkowski , Giuseppe Buja , “ Review of direct torque control methods for voltage source inverter-fed induction motor” ' IEEE, 2003, pp.981-991.

[15] Shady M. Gadoue , D. Giaouris , J.W. Finch , “ Tuning of PI speed controller in DTC of induction motor based on genetic algorithms and fuzzy logic schemes", IEEE , 2006, pp.

[16] Abdelnassir Abdalla , “ Torque ripple minimization in direct torque control of induction machines", Master thesis, Ohio state university, May 2005. 